\title{
Analysis of Low Dose Aspirin on Platelet Aggregation Percentage in High-Risk Pregnancy Hypertension
}

\section{Oktaviany Irma Wiputri ${ }^{1{ }^{1 *}}$, Yulistiani ${ }^{1}$, Eddy Z Monsir ${ }^{2}$, Dewi Ramdani ${ }^{3}$}

\author{
${ }^{1}$ Department of Clinical Pharmacy, Faculty of Pharmacy, Universitas Airlangga, Mulyorejo, Surabaya, Indonesia; \\ ${ }^{2}$ Department of Obstetrical and Gynaecology, Haji Teaching Hospital, Mulyorejo, Surabaya, Indonesia; \\ ${ }^{3}$ Department of Pharmacy, Haji Teaching Hospital, Mulyorejo, Surabaya, Indonesia.
}

\section{ARTICLE INFO:}

Received: 05 Feb 2021

Accepted: 14 Feb 2021

Published: 28 Feb 2021

\section{Corresponding author *} Oktaviany Irma Wiputri, Department of Clinical Pharmacy, Faculty of Pharmacy, Universitas Airlangga, Kampus C, UNAIR, Mulyorejo, Surabaya, Indonesia E Mail:

oktavianyirmawiputri@gmail.com

\begin{abstract}
:
Objective: Low dose aspirin (LDA) is one of platelet aggregation agents in high-risk pregnancy that is believed to prevent complication by inhibiting thromboxane A2 as a strong vasoconstrictor in platelet. It can inhibit platelet aggregation involved in pathophysiology of pregnancy hypertension. The aim of this study is to analyse the effect of LDA on platelet aggregation in pregnant patient with high-risk hypertension.

Material and methods: A prospective observational method was conducted in this study. It was approved by the Ethics Committee of Haji Teaching Hospital Surabaya. Data was collected from July to September 2018 involving 18 patients divided into three groups who have age of 35-39 years old in the majority. The range of gestational age in this study was 19-37 weeks. Platelet aggregations on plasma were measured before and $14-30$ days after LDA use. The collected data were statistically analyzed by using a paired t-test.

Results: Platelet aggregation percentage using collagen agonists was an increase of $0.8 \%(p>$ $0.05)$ in the old patient group and followed by $6 \%(\mathrm{p}>0.05)$ in the group of patients who did not get LDA. Whereas in the group of new patients showed a decrease of $6 \%(p>0.05)$. While ADP agonists showed that the group of new patients decreased by $17 \%(p>0.05)$, followed by the group of patients who did not use LDA of $9 \%(p>0.05)$ and the old patient group was $4 \%$ $(\mathrm{p}>0.05)$.

Conclusions: Low-dose aspirin use did not affect a decrease in platelet aggregation values.
\end{abstract}

Keywords: high risk pregnancy, low-dose aspirin, platelet aggregation.

\section{INTRODUCTION}

Pregnancy in high-risk hypertension is a risk of complication in preeclampsia (PE) to eclampsia (E). PE is the secondary causes of maternal mortality that can occur in $1-8 \%$ of pregnant women in worldwide, one of the five causes of maternal mortality in developing countries [1-3].As the Indonesian Demographic and Health Survey (IDHS), the 2012 maternal mortality rate showed a significant increase from 228 to 359 maternal deaths per 100,000 live births. The proportion of hypertension in pregnancy (HP) as one of the biggest causes of maternal fatality in Indonesia increased significantly in 2013 [4].

HP shows an overview of endothelial dysfunction, the risk of thrombosis that triggers an imbalance between PGI2 (vasodilator) and TXA2 (vasoconstrictor) in utero-placental and systemic. This process continues until platelet hyperaggregation occurs due to platelet hyper activation and hypercoagulation [5-9]. Platelets have prominent role in the etiology of PE because of their involvement in the homeostasis and thrombosis processes [10-12]. In patients who are at high risk of PE, a decrease in PGI2 and an increase in TXA2 are seen at week 13 of gestation. One of the clinical manifestations of increased platelet aggregation in PE occurs after week 20 of gestation [13].

The prevalence and pathogenesis of the occurrence of $\mathrm{PE}$ underlie a particular treatment. Prevention or delay of PE can be done by providing prophylactic therapy, namely platelet anti-aggregation drugs [14]. The recommended antiaggregation of platelets is LDA (75-162 mg / day) [15]. LDA can neutralize the TXA2 / PGI2 imbalance within 2 weeks in prothrombotic conditions [9]. A meta-analysis research conducted by Henderson-smart, et al. (2010) involving 59 trials showed that low-dose aspirin $(75 \mathrm{mg})$ reduced the risk of PE by $17 \%$, with a similar reduction in the risk of death in infants (14\%) and a decrease in the risk of premature birth $(8 \%)$. The use of LDA is used as a 
International Journal of Pharma Research and Health Sciences, 2021; 9 (1): 3286-3290

prevention of blood clots because there is a blood clotting process that appears in preeclamptic conditions which can cause serious further complications [16].

This study aimed to analyze the effect of using low-dose LDA on the percentage of platelet aggregation by examining the ex vivo platelet response to various agonists. Platelet aggregation is the most useful in vitro test for platelet function tests today and is still the gold standard for detecting platelet disorders [17]. This study is expected to provide an overview of platelet activation or aggregation and information on the use of low-dose LDA in the prevention of $\mathrm{PE}$ in patients with high-risk pregnancy for hypertension so that it can be used as a clinical practice guide. In addition, giving low doses of LDA is expected to be effective in preventing PE during pregnancy by using the percentage marker of platelet aggregation.

\section{MATERIALS AND METHOD}

This research is a prospective observational study with a longitudinal design that has been declared ethical clearance by the health research ethics committee of Surabaya Haji Hospital with the number: 073/10 / KOM.ETIK / 2018. The research sample with the criteria attached to Table 1 was carried out at the Obstetrical and Gynecology Clinic of the Haji Hospital and Wonokromo Primary Health Center, Surabaya in July-September 2018.

Table 1: Research Sample Criteria

\begin{tabular}{|c|c|c|}
\hline \multicolumn{3}{|l|}{ Sample Criteria } \\
\hline Inclusion & Exclusion & Drop Out \\
\hline 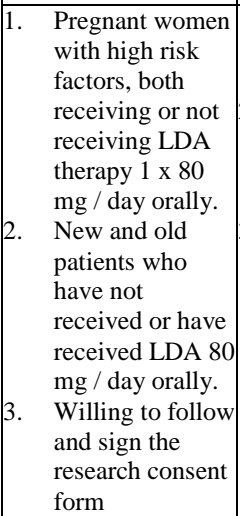 & \begin{tabular}{|l} 
1. \\
Patients on other anti- \\
aggregation/anticoagulant \\
therapy. \\
2. $\begin{array}{l}\text { Patients with } \\
\text { thrombocytopenia, heart } \\
\text { disease, HELLP } \\
\text { syndrome. } \\
\text { 3. Patients on NSAID or } \\
\text { cortico-steroid therapy }\end{array}$ \\
\end{tabular} & 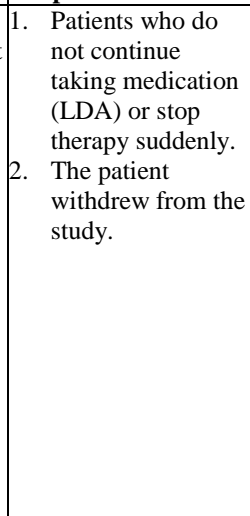 \\
\hline
\end{tabular}

In this study, 18 sample was divided into three groups, (1) new patient group is pregnant women at high risk of hypertension who did not taken acetosal $80 \mathrm{mg} / \mathrm{day}$, (2) old patient group that took acetosal $80 \mathrm{mg} /$ day and (3) group patient who did not take acetosal $80 \mathrm{mg} /$ day.

The patient's blood sample in the form of plasma will be observed the value of $\%$ platelet aggregation using Light Transmission Aggregometry (LTA) with the addition of collagen agonists as strong agonists and ADP as weak agonists through different platelet activation pathways. Plasma was collected twice, namely before and after using
LDA within a period of 14-30 days. The $\%$ platelet aggregation data obtained will be analyzed statistically.

\section{RESULTS}

The study sample is 18 patients, divided into 3 groups, namely 4 new patients, 9 old patients and 5 patients who did not receive $80 \mathrm{mg} /$ day LDA therapy. Patient characteristics are often found include (1) maternal age (35-39 years) with a mean gestational age of $28.944 \pm 6.254$ weeks, (2) a history of multiparity (1-3) with a mean of $1.611 \pm 1.243$ parity, (3) Body Mass Index (> $30 \mathrm{~kg} / \mathrm{m} 2$ ), (4) signs of pregnancy risk (edema, proteinuria, and MAP), (5) other clinical features such as dizziness, pain in waist, and pain in neck, (6) duration of LDA therapy with a mean 5,667 $\pm 6,380$ days at a dose of $80 \mathrm{mg} /$ day, and (7) a history of contraception use including injections, pills, and IUD.

In this study, the \% value of platelet aggregation was obtained against two agonists. Figure 1 shows the $\%$ platelet aggregation against collagen agonists has increased by $0.8 \%$ (from $69,556 \pm 21,308$ to $70,111 \pm 21,115$ ) in the old patient group and $6 \%$ (from $76,000 \pm 20,322$ to $80,400 \pm 15,598$ ) in the group of patients who did not get LDA, whereas in the new patient group it decreased by $6 \%$ (from 82,250 $\pm 19,568$ to $78,000 \pm 16,145)$. Distribution of $\%$ platelet aggregation to collagen agonists in three patient groups was in the hyperaggregation, normoaggregation, and hypoaggregation ranges.

The assessment of $\%$ platelet aggregation against ADP agonists is presented in Figure 2 show a decrease in the three groups, namely $17 \%$ (from $103,250 \pm 7,932$ to $85,500 \pm$ 22,398 ) in new patients, $4 \%$ (from $86,111 \pm 15,243$ to $82,889 \pm 22,740$ ) in old patients, and $9 \%$ (from 100,000 \pm 12,083 to $90,800 \pm 11,367$ ) of patients not receiving LDA. The distribution of the $\%$ value of platelet aggregation against ADP agonists shows a tendency to be in the hyperaggregation range.

Measurement of $\%$ platelet aggregation is important to determine the control of increased platelet aggregation. Statistical analysis of the \% platelet aggregation observed before and after aims to determine the significance of the change in $\%$ platelet aggregation that occurs. The results of the analysis are listed in Figures 1 (Collagen Agonists), which shows that there is no significant difference in the \% of platelet aggregation before and after in the new patient group ( $p=0.771)$, old patients $(p=0.889)$, and patients who do not use LDA $(\mathrm{p}=0.578)$. Whereas in Figures 2 (ADP agonists) there was no significant difference in the $\%$ platelet aggregation in the new patient groups $(p=0.105)$, old patients $(\mathrm{p}=0.698)$, and patients who did not use LDA $(\mathrm{p}=$ $0.237)$. 


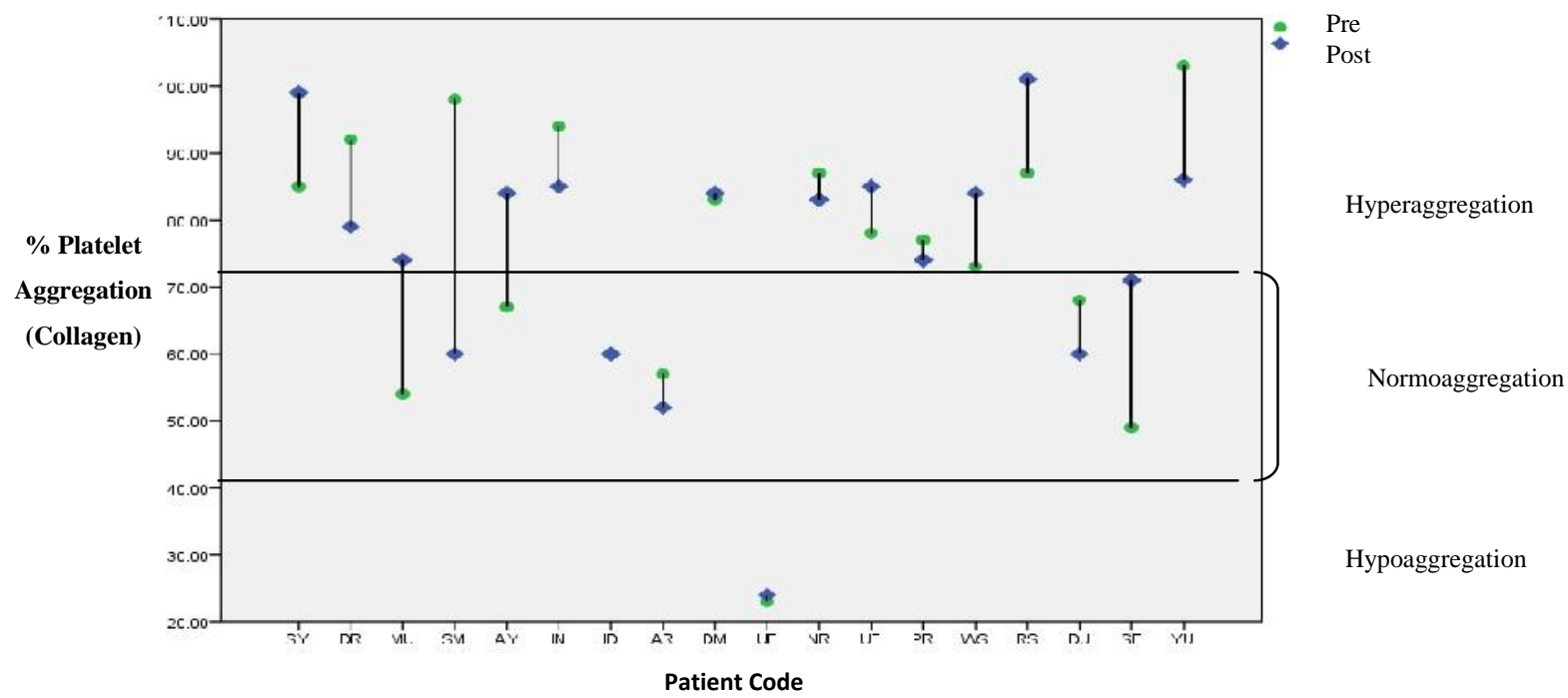

Fig 1: Platelet Aggregation Percentage (\%) Profiling in Collagen

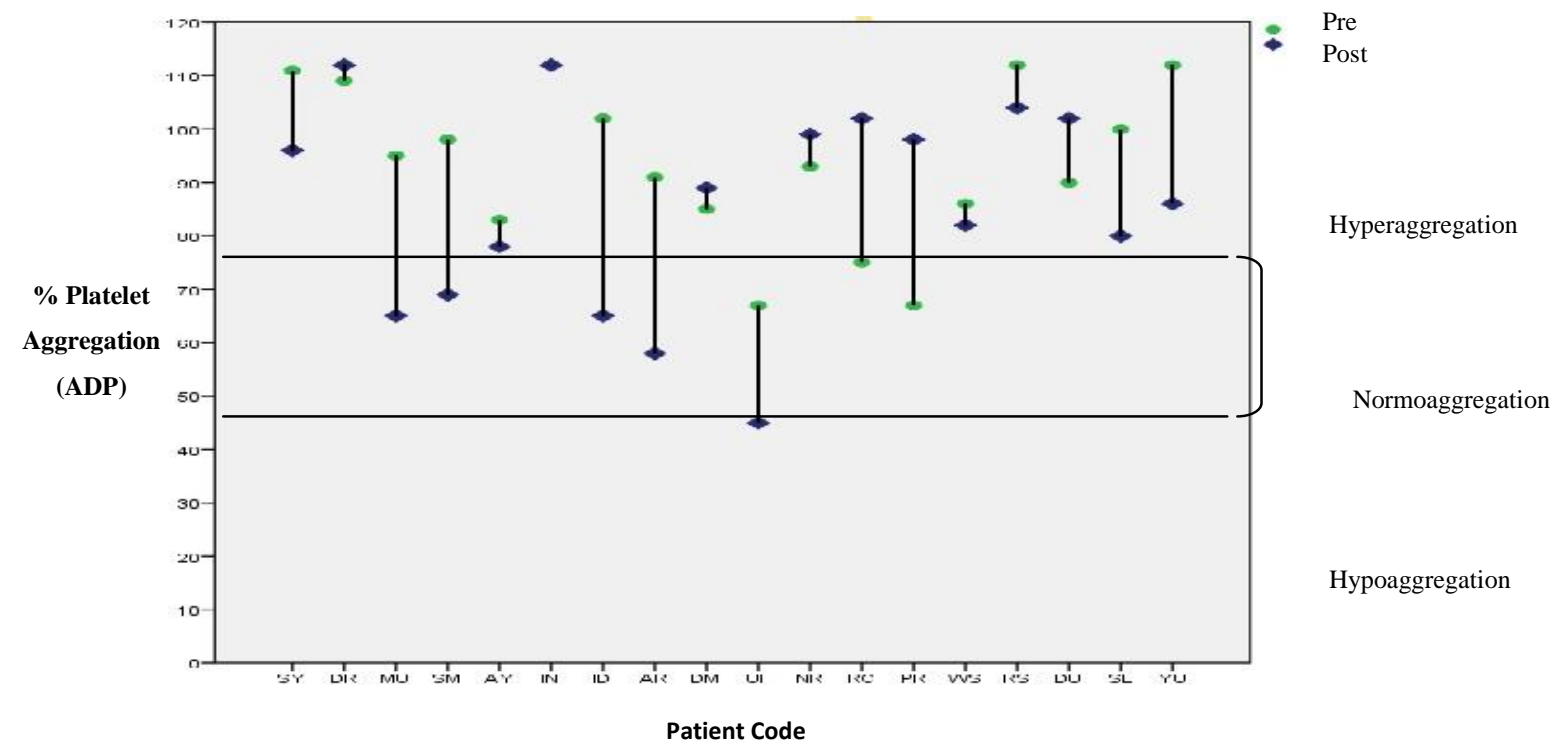

Fig 2: Platelet Aggregation Percentage (\%) Profiling in ADP

\section{DISCUSSION}

Platelet hyperactivation and hypercoagulation conditions trigger the risk of thrombosis which is the basic mechanism for various pregnancy complications, such as PE [6]. Changing in the balance of PGI2 and TXA2 were seen at 13 weeks' gestation in patients at high risk of PE. A decrease in PGI2 and an increase in TXA2 production triggers uteroplacental and systemic vasoconstriction as well as increased platelet aggregation and decreased uteroplacental blood flow [7-9]. One of the clinical manifestations of PE is that there is an increase in platelet aggregation at more than 20 weeks of age [13].
Measurement of \% platelet aggregation in this study used two agonists, namely collagen and ADP. Collagen is a strong agonist that directly induces platelet aggregation, TXA2 synthesis, and secretion of platelet granules. Based on theory, the aggregation method using collagen agonists is more sensitive in evaluating the effects of acetosal [18]. While ADP is a weak agonist that induces platelet aggregation without causing secretion of platelet granules [12].

The different agonists indicate the location of the injured blood vessel wall and play a role in the overall platelet adhesion process. The platelet adhesion process begins with exposure to the matrix components (collagen and vWF) on 
International Journal of Pharma Research and Health Sciences, 2021; 9 (1): 3286-3290

the blood vessel walls with receptors on the platelet surface membrane. Platelet activation occurs after the agonist binds to its receptors. Collagen agonists bind to the GPVI receptors and $\alpha 2 \beta 1$ integrin, while ADP agonists bind to the P2Y12 and P2Y1 receptors on the platelet surface [19].

Changing in the $\%$ value of platelet aggregation was tested by statistical analysis to determine the significance of changes before and after that occurred. Statistical analysis used for data processing in each group used the Wilcoxon signed rank test. The results of statistical analysis, there was no significant difference in this study, showed that the value of $\%$ platelet aggregation in the group of patients who received therapy (new patients and old patients) was influenced by one factor of the time to start LDA therapy which varied. In this study, the initiation of LDA therapy was from weeks 12 of gestation to weeks 37 . The metaanalysis reported that of 45 randomized control trials, lowdose acetosal started after 16 weeks of gestation showed a moderate reduction in preeclampsia, whereas use before weeks 16 showed a significant reduction in severe preeclampsia and foetal growth restriction. Meanwhile, another meta-analysis stated that the decrease only occurred in the group who started LDA therapy before 16 weeks of gestation at a dose of $100 \mathrm{mg}$ or more [20].

Several supporting studies gave results that platelet aggregation increased significantly from the first to the third trimester in response to collagen agonists $(\mathrm{P}<0.001)$ and arachidonic acid $(\mathrm{P}<0.001)$. Arachidonic acid acts via the COX TXA2 pathway to induce platelet aggregation. Platelets showed increased reactivity to arachidonic acid in the second and third trimesters of this study. Increased aggregation of arachidonic acid explains that in the condition of pregnancy there is a picture of a prothrombotic condition. The results provide evidence that platelet reactivity during pregnancy changes when compared to nonpregnant conditions and these changes depend on gestational age and agonist compounds to activate platelets [11].

Another study is a prospective study gave results that the effect of collagen agonist compounds, arachidonic acid, and epinephrine on platelet activation in the aspirin group and the group that did not receive aspirin showed a significant difference $(\mathrm{P}<0.0001)$. The difference in agonist compounds affected the results of the percentage of aggregation obtained, namely for the ADP compound $83.8 \%$, collagen $74.8 \%$, arachidonic acid $77.9 \%$, and epinephrine by $72 \%$ in the group that did not get aspirin. This study used a pharmacodynamic effect using low-dose acetosal $(81 \mathrm{mg})$ which targets platelet function during pregnancy [21, 22]. Limitations in this study included the small sample size, limited study time, different types of risk factors, comorbid or complicated complications, disease severity, varying gestational age and initiation of LDA therapy and the level of adherence for each patient. This is because the average patient has entered a sufficient gestational age, LDA that has been given in previous health facilities, so that these factors cannot be controlled during the study. The number of samples is too small and the homogeneity of patient characteristics causes the results of the data analysis to be insignificant, so it is suggested that further research can be done with a larger sample size and can be done at a younger gestational age to see the progress of the disease and the effectiveness of LDA therapy given.

\section{CONCLUSION}

This study confirmed the use of low-dose acetosal as a preventive therapy in high-risk pregnant women does not affect the decrease in the platelet aggregation percentage value for either patients who have not taken acetosal yet or patients who have received it.

\section{REFERENCES}

1. Askie LM, Duley L, Henderson-Smart DJ, Stewart LA. Antiplatelet agents for Prevention of Pre-eclampsia: A Meta-Analysis of Individual Patient Data. Lancet Glob Health 2007; 369: 1791-8.

2. Say L, Chou D, Gemmill A, Tunc AO, Moller AB, Daniels J, et al. Global causes of maternal death: a WHO systematic analysis. Lancet Glob Health 2014; 2: e323-33.

3. Von Dadelszen P, Magee LA. Pre-eclampsia: an update. Curr Hypertens Rep 2014;16:1-14.

4. Kementerian Kesehatan Republik Indonesia. Kesehatan Keluarga In: 2015 Profil Kesehatan Indonesia. Kementerian Kesehatan Republik Indonesia: Jakarta; 2016:114-8.

5. Cai H, Harrison DG. Endothelial Dysfunction in Cardiovascular Disease. Circ Res 2000; 87:840-4.

6. Al Obaidly M, Regan C, Lwaleed B, Moran N. A Role for Platelets in Normal Pregnancy. Intech Open 2015; 159-67.

7. Atallah A, Lecarpentier E, Goffinet F, Doret-Dion M, Gaucherand P, Tsatsaris V. Aspirin for Prevention of Preeclampsia. Drugs 2017; 77: 1819-31.

8. Navaratnam K. Platelet function and response to lowdose aspirin in Pregnancy. University of Liverpool. 2017;12-73.

9. Sava RI, March KL, Pepine CJ. Hypertension in Pregnancy: Taking cues from pathophysiology for clinical practice. Clin Cardiol 2018; 41: 221.

10. Siddqui IA, Jaleel A, Tamimi W, Al Kadri HMF. Role of oxidative stress in the pathogenesis of Preeclampsia. Obstet Gynecol. 2010; 282: 472.

11. Burke N, Flood K, Murray A, Cotter B, Dempsey M, Fay L, et al. Platelet reactivity changes significantly throughout all trimesters of Pregnancy compared with the non Pregnant state: a prospective study. Int J Gynaecol Obstet 2013;120:599-1604.

12. Golebiewska EM, Poole AW. Platelet secretion: From haemostasis to wound healing and beyond. Blood Rev $2015 ; 29: 153$. 
International Journal of Pharma Research and Health Sciences, 2021; 9 (1): 3286-3290

13. Possomato-Vieira JS, Khalil RA. Mechanism of Endothelial Dysfunction in Hypertensive Pregnancy and Preeclampsia In : Khalil, R.A. Endothelium. $1^{\text {st }}$ edition. United Kingdom: Elsevier; 2016:367-408.

14. Lowe SA, Bowyer L, Lust K. The SOMANZ Guideline for the Management of Hypertensive Disorders of Pregnancy. https://www.somanz.org/documents/HTPregnancyGuid elineJuly2014.pdf (Accessed Mar 20, 2018).

15. Magee LA, Pels A, Helewa M, Rey E, von Dadelszen P. Diagnosis, Evaluation, and Management of the Hypertensive Disorders of Pregnancy: Executive Summary. J Obstet Gynaecolog Can 2014; 36: 416-38.

16. Henderson-smart DJ, Duley L, Meher S, King JF. Antiplatelet agents for Preventing Pre-eclampsia and its complications. Cochrane Database Syst Rev 2007; 2: CD004659

17. Frontroth JP. Light Transmission Aggregometry In: Monagle, P. Haemostasis Methods and Protocol. London: Springer; 2013: 227-40.

18. Kinouchi K, Fujita T, Narahara C, Kitamura S. Platelet function in pregnant women receiving aspirin and dipyridamole. J Anesth 2000; 14: 115-8.

19. Koltai K, Kesmarky G, Feher G, Tibold A, Toth K. Platelet aggregometry testing: Molecular mechanism, technique, and clinical implications. Int J Mol Sci 2017;18:1-2.

20. ACOG Hypertension in Pregnancy. Report of the American College of Obstetricians and Gynecologists' Task Force on Hypertension in Pregnancy. Am J Obstet Gynecol 2013; 122: 1122-31.

21. Patil A, Thames E, James A. Pharmacodynamics of low-dose aspirin in Pregnancy. Am J Obstet Gynecol. 2012; S329.

22. Practical-Haemostasis. https://practicalhaemostasis.com (Accessed Jan 25, 2018).

CONFLICT OF INTEREST: The authors declare no conflict of interest, financial or otherwise.

SOURCE OF FUNDING: None.

AVAILABILITY OF DATA AND MATERIALS: Not applicable.

CONSENT FOR PUBLICATION: Not applicable.

ETHICS APPROVAL AND CONSENT TO

PARTICIPATE: 073/10 / KOM.ETIK / 2018. 